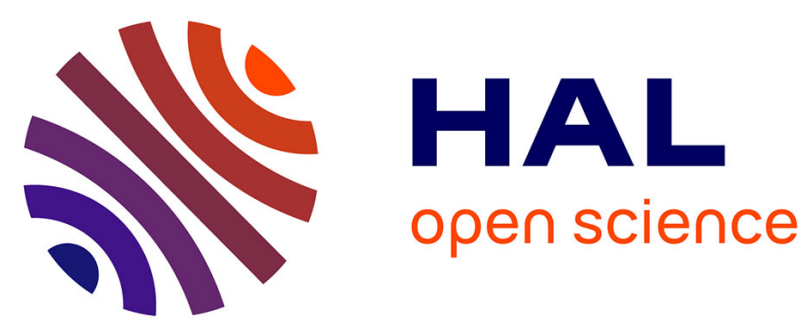

\title{
The transferability of Australian pedotransfer functions for predicting water retention characteristics of French soils.
}

\author{
H.P. Cresswell, Yves Coquet, Ary Bruand, N.J. Mackenzie
}

\section{- To cite this version:}

H.P. Cresswell, Yves Coquet, Ary Bruand, N.J. Mackenzie. The transferability of Australian pedotransfer functions for predicting water retention characteristics of French soils.. Soil Use and Management, 2006, 22 (1), pp.62-70. 10.1111/j.1475-2743.2006.00001.x . hal-00020213

HAL Id: hal-00020213

https://hal-insu.archives-ouvertes.fr/hal-00020213

Submitted on 5 Apr 2006

HAL is a multi-disciplinary open access archive for the deposit and dissemination of scientific research documents, whether they are published or not. The documents may come from teaching and research institutions in France or abroad, or from public or private research centers.
L'archive ouverte pluridisciplinaire HAL, est destinée au dépôt et à la diffusion de documents scientifiques de niveau recherche, publiés ou non, émanant des établissements d'enseignement et de recherche français ou étrangers, des laboratoires publics ou privés. 
1 Manuscript for submission to: Soil Use and Management

2

3

4

5

6

8

9

10

11

12

13

14

15

16

17

18

19

20

21 1
The transferability of Australian pedotransfer functions for predicting water retention characteristics of French soils

.

0

1 H.P. Cresswell ${ }^{*}$, Y. Coquet $^{2}$, A. Bruand ${ }^{3}$ \& N.J. McKenzie ${ }^{1}$

${ }^{1}$ CSIRO Land and Water, GPO Box 1666, ACT 2601, Australia.

$5{ }^{2}$ UMR INRA/INAPG Environment and Arable Crops, Institut National de la

6 Recherche Agronomique/Institut National Agronomique Paris-Grignon,

17 Thiverval-Grignon, France.

$8{ }^{3}$ Institut des Sciences de la Terre d'Orléans (ISTO), Université d'Orléans,

9 Géosciences, BP 6759, 45067 Orléans Cedex 2, France.

20 * Corresponding author: Fax +61 2 6246 5965, E-mail hamish.cresswell@ csiro.au 
1 Abstract. A French data set was used in evaluating how well two widely used

2 analytical functions describe measured soil water characteristic (SWC) data. Both the

3 van Genuchten (sigmoidal) and Campbell (power-law) equations gave good

4 descriptions of the data (mean $\mathrm{R}^{2}$ of $98.1 \%$ and $97.1 \%$ respectively). Methods of

5 predicting SWC data were also evaluated. When a power-law equation was

6 parameterised using just two measured SWC points and bulk density (the 'two-point'

7 method), a very good SWC prediction was obtained for the French data (mean $\mathrm{R}^{2}$ of

$894.8 \%$ ). An empirical equation for prediction of the SWC was also assessed using the

9 French data set. This method was developed using multiple regression analysis from

10 Australian soil data and requires soil texture and bulk density as input. The

11 predictions (mean $\mathrm{R}^{2}$ of $85.2 \%$ ) lacked accuracy and precision in comparison to the

12 two-point method but uses more readily available input data. The accuracy of

13 prediction from both methods was similar to that observed previously for Australian

14 data sets. The empirical approach developed from Australian soil data has reasonable

15 applicability to French soils. The approach of assuming a power-law model and

16 empirically predicting slope and air entry potential is shown to have merit. A strategy

17 for achieving adequate coverage of soil hydraulic property data for France is

18 suggested incorporating hydraulic prediction methods such as those evaluated here.

20 Keywords: soil water characteristic, water retention, prediction, pedotransfer

21 function 
2 Soil hydraulic property data is a requirement for models simulating water and

3 chemical transport in soil. With the increased application of such models, as well as

4 for climate impact modelling, land resource assessment, and regional risk assessment

5 there is a growing demand for soil hydraulic data in France and elsewhere. It would

6 be ideal to have detailed soil and land information at scales relevant to management

7 (e.g. similar to the existing coverage in The Netherlands) but obtaining such coverage

8 in France is a huge task. The soil water characteristic (SWC) can only be measured at

9 a limited number of sites during a routine survey because of time and cost. Strategies

10 for acquiring appropriate hydraulic data have to balance the costs of detailed direct

11 measurement against the reduced accuracy and precision of using minimal direct

12 measurement with simple extrapolation, or alternatively adopting indirect methods for

13 estimation.

14 In France Bruand et al. (2003) have recently developed pedotransfer functions

15 (PTFs) that use texture and bulk density to predict gravimetric water content at seven

16 matric potentials ranging from -0.10 to $-150 \mathrm{~m}$ of water. Apart from Bruand (1990),

17 Bruand et al. (1994) and Bruand et al. (2004) there are few other examples of the

18 development of PTFs for French soils. In Australia systems developed for predicting

19 the SWC for Australian soils from morphological data, or from combinations of

20 physical and morphological data, include those of Williams et al. (1992), Cresswell

21 and Paydar (1996), Paydar and Cresswell (1996), Smettem and Gregory (1996) and

22 Minasny et al. (1999). These approaches have often aimed to predict the variables in

23 models of the soil water characteristic.

24 Most mechanistic soil water simulation models adopt one or more closed-form

25 models for describing soil hydraulic properties and using them in solutions of soil 
1 water flow equations. In Australia the hydraulic models of Campbell (1974) have

2 been widely used both in soil water simulation models and in methods for predicting

3 soil hydraulic properties. The Campbell equations have been favoured due to their

4 simplicity and adequacy of description of measured hydraulic data (e.g. Cresswell and

5 Paydar 1996). The model of van Genuchten (1980) is also in widespread usage. For

6 the use of closed-form equations describing soil hydraulic properties to be effective in

7 either simulation modelling or with continuous PTFs, such equations must give a

8 good description of measured soil hydraulic data.

9 The aim of this work was to use the French soil hydraulic database of Bruand et al.

10 (2003) and:

11 (a) test the utility of closed-form hydraulic models for describing the soil water

12 characteristics of French soils,

13 (b) assess the effectiveness of methods developed in Australia for the prediction of

14 water characteristics of French soils, and

15 (c) suggest a role for such prediction methods within a strategy for the hydraulic

16 characterisation of French soils.

The data set

20 The soil data set used for this study was that of Bruand et al. (2003) and contains

21 Cambisols, Luvisols and Fluvisols (ISSS Working Group RB 1998) mainly from the

22 Paris Basin with some from western coastal marshlands and from the Pyrenean

23 piedmont plain. The data set available contained 445 horizons, but for this analysis a 
1 subset was used containing 144 horizons - 34 A-horizons, 64 B-horizons, 35 C-

2 horizons and 11 E-horizons. The samples used as they map to the texture triangle are

3 shown in Figure 1.

4 The generation of soil water characteristic curves and supporting data for these

5 samples is as described by Bruand et al. (2003). The horizons were sampled in winter

6 when close to field capacity. Undisturbed samples $100-1000 \mathrm{~cm}^{3}$ in volume were

7 collected. Clods $5-10 \mathrm{~cm}^{3}$ in volume were separated by hand from the stored samples.

8 The dry bulk density of the clods as collected was determined using the kerosene

9 technique of Monnier et al. (1973). Then gravimetric water contents (g water per $\mathrm{g}$

10 oven dried soil) were determined at seven matric potentials: $-0.10,-0.33,-1.0,-3.30$,

$11-10.0,-33.0,-100$, and $-150 \mathrm{~m}$ using pressure plate or pressure membrane apparatus.

12 Clods were placed on a paste made from $<2 \mu \mathrm{m}$ particles of kaolinite to establish

13 continuity of water between the clods and the pressure plate or membrane (Bruand et

14 al. 1996). Water content was expressed as a percentage of the dry mass of the sample

15 after oven drying at $105^{\circ} \mathrm{C}$ for 24 hours. Twelve to fifteen clods were used for each

16 sample to determine the mean water contents at each matric potential value. The bulk

17 density as determined at -3.30 m matric potential was used to convert gravimetric soil

18 water contents into volumetric values, unless this measure was unavailable, when bulk

19 density determined at time of sampling was used.

$21 \quad$ (Figure 1 near here)

23 Particle size distribution was measured using the pipette method after pre-treatment 24 with hydrogen peroxide and sodium hexametaphosphate (Robert and Tessier 1974). 
2 The soil hydraulic models

3 Campbell (1974) proposed a function to describe the relation between volumetric soil

4 water content $(\theta)$ and soil matric potential $(\psi)$ :

5

6

$$
\theta=\theta_{s}\left(\frac{\psi}{\psi_{e}}\right)^{-\frac{1}{b}}
$$$$
\psi<\psi
$$

7

$$
\theta=\theta_{s}
$$$$
\psi \geq \psi_{e}
$$

8

9 where $\theta_{\mathrm{s}}$ is water content at field saturation, $\psi_{\mathrm{e}}$ is air entry potential, and $b$ is a constant. The Campbell function can also be written as (Williams et al. 1992):

11

12

$$
\ln \theta=A+B \ln |\psi| \quad \psi<\psi_{e}
$$

13

$$
\theta=\theta_{s} \quad \psi \geq \psi_{e}
$$

15 where:

16

$$
A=\ln \theta_{s}+\frac{1}{b} \ln \left|\psi_{e}\right|
$$

$$
B=-\frac{1}{b}
$$

19 Various sigmoidal curves have also been used to describe soil water retention data

20 including the popular model of van Genuchten (1980) (5), which allows derivation of

21 closed-form analytical expressions for hydraulic conductivity. The equation gives a 
1 sigmoidal curve between field saturated water content $\theta_{\mathrm{s}}$ and residual water content

$2 \theta_{\mathrm{r}}$ :

$$
\theta=\theta_{r}+\frac{\theta_{s}-\theta_{r}}{\left(1+(\alpha \psi)^{n}\right)^{m}}
$$

$6 \quad$ where $\alpha, n$ and $m$ are empirical parameters. $\alpha$ approximates the inverse of the air

7 entry potential when $m / n$ values are small. Equation (5) can be used with $m$ and $n$ as

8 independent variables although unique relations between $m$ and $n$ are more commonly

9 assumed because they allow simplification of solution for hydraulic conductivity models. Here we use $m=1-1 / n$ as proposed by van Genuchten (1980).

The two-point method of Cresswell and Paydar (1996) for determining the soil water characteristic

14 Cresswell and Paydar (1996) proposed a method of soil water characteristic determination called the 'two-point' method. The method predicts a Campbell (1974) SWC function using two measured $\theta(\psi)$ points plus a $\theta_{\mathrm{s}}$ value. A straight line is fitted through the two measured $\theta(\psi)$ points on a $\ln$-ln scale (Ahuja et al. 1985). In this study different pairs of measured points were assessed for use in the 'two-point' method, (a) -3.30 and $-150 \mathrm{~m}$, and (b) -1.00 and $-150 \mathrm{~m}$. These points were not always available for all 144 samples used from the Bruand et al. (2003) data set; the

21 analysis reported only includes the samples that had both of the required match points $(n=127$ samples for -3.30 and -150 m match points; $n=118$ for -1.00 and $-150 \mathrm{~m}$ match points). The value of $b$ is obtained directly from the slope of the straight line

24 from the two-point fit. $\psi_{\mathrm{e}}$ is evaluated as the $\psi$ value at which $\theta$ equals the measured 
1 or estimated value of $\theta_{\mathrm{s}}$. The predicted Campbell SWC curve is smoothed using the method of Hutson and Cass (1987) as described in Cresswell and Paydar (1996).

4 The method of Williams et al. (1992) for predicting the soil water characteristic

5 Williams et al. (1992) developed eight sets of empirical equations for the prediction

6 of the constants $A$ and $B$ in the Campbell function (2). The equations were

7 subsequently evaluated by Paydar and Cresswell (1996) using an Australian data set.

8 Function 4 of Williams et al. (1992) performed the best of the eight functions and is

9 selected for use in this study. Function 4 was developed from the data set of Prebble

10 (1970) which contained 78 soil horizons from 17 soil profiles in northern Australia.

11 Of these, 34 horizons had clay content between 50 and $75 \%$. The regression

12 equations require particle size distribution, field texture and bulk density inputs and 13 are defined as follows:

14

18

$$
\begin{aligned}
& A=1.996+0.136(\ln C)-0.00007\left(F S^{2}\right)+0.145(\ln S I)+0.382(\ln T E X) \\
& B=-0.192+0.0946(\ln T E X)-0.00151(F S)
\end{aligned}
$$

$\mathrm{C}$ is \% clay $(<0.002 \mathrm{~mm})$; $\mathrm{SI}$ is \% silt $(0.002-0.02 \mathrm{~mm})$; FS is \% fine sand $(0.02-0.20$ $\mathrm{mm}$ ), and TEX is texture group from 1-6 as defined by Northcote (1971). Units of $\theta$ and $\psi$ used in these functions are percentage (volumetric) and bar respectively. The values of $A$ and $B$ are used in equation 2 together with a value for $\theta_{\mathrm{s}}$ which is usually estimated from bulk density assuming particle density of $2.65 \mathrm{Mg} \mathrm{m}^{-3}$ and an air entrapment multiplier. 
2 Firstly the Bruand et al. (2003) SWC data (445 horizons) were carefully screened to

3 determine suitability for this analysis. This process involved checking that a

4 satisfactory bulk density measurement was available, that none of the volumetric

5 water contents exceeded total porosity, checking that water content did not increase as

6 matric potential became more negative, and making sure that there were a minimum

7 of 5 SWC points that could be used for the fitting analysis. On the basis of this

8 screening a substantial number of individual samples were excluded, and some

9 samples were modified by removing pairs of $\theta(\psi)$ data when it appeared warranted,

10 i.e. where measurement error was suspected. Following the screening 144 samples

11 were selected for further analysis. Each sample had between 5 and 8 measured SWC

12 points that could be used for fitting (11 samples had 5 SWC points, 39 samples had 6

13 points, 59 samples had 7 points, and 35 samples had 8 points).

14 The soil water content at saturation was assumed to equal total porosity

15 (determined from bulk density which was measured on intact clods at $-3.30 \mathrm{~m}$ matric

16 potential) multiplied by 0.95 to allow for air entrapment. Particle density was

17 assumed to equal $2.65 \mathrm{Mg} \mathrm{m}^{-3}$.

18 Equations 1 and 5 were fitted to the SWC data with a non-linear, least squares

19 curve fitting program 'RETC' (van Genuchten et al. 1991). RETC was slightly

20 modified for fitting the Campbell function in that the bounds for one of the fitting

21 constants $(n)$ was altered from that required when RETC is used to fit the van

22 Genuchten SWC curve. Water content at saturation was fixed rather than optimised

23 for all of the fitting reported here. RETC was run with MTYPE=5 to fit the Campbell

24 equation (1), and with MTYPE=3 to fit the van Genuchten equation (5); i.e. with the

25 Mualem restriction of $m=1-1 / n$. Where $\theta_{\mathrm{r}}$ in equation 5 tended to zero during the 
1 optimisation process it was fixed at zero before the optimisation recommenced using

2 only $\alpha$ and $n$ as variables.

3 The goodness of fit to the measured SWC data of the Campbell and van Genuchten

4 functions was then evaluated. The equation variables, once determined, were used to

5 calculate the fitted soil water contents at each matric potential so that they could be

6 compared with the original measured SWC data points. The measured $\theta(\psi)$ values

7 were compared with the predicted $\theta(\psi)$ values. For each individual measured $\theta(\psi)$

8 point on each SWC, the residual was determined as the measured $\theta(\psi)$ value minus

9 the predicted value. The measured values were regressed against the fitted (or

10 predicted) values. Root mean square error (RMSE) was determined as follows:

$$
R M S E=\sqrt{\frac{\sum_{i=1}^{n}\left(\left|x_{i}-y_{i}\right|\right)^{2}}{n}}
$$

13 The mean absolute value of the residuals and the mean of the residuals was

14 determined before the residuals were regressed against the fitted values and the slope

15 and intercepts were evaluated. Individual outlier $\theta(\psi)$ pairs were discarded if having 16 undue influence on the regression analysis.

17 The mean absolute value of the residuals (MAE) quantifies the absolute magnitude 18 of error from the use of predicted $\theta(\psi)$ data:

$$
M A E=\left(\frac{1}{n}\right) \sum_{i=1}^{n}\left(\left|x_{i}-y_{i}\right|\right)
$$


1 where $x_{i}$ is a measured $\theta$ point and $y_{i}$ is a predicted (or fitted) $\theta$ point both for the

2 same matric potential and from the same soil sample. Small $M A E$ values indicate

3 little difference between predicted (or fitted) and measured $\theta(\psi)$ data.

4 The two-point method was applied as described previously including the use of the

5 Hutson and Cass (1987) equation to smooth the predicted Campbell SWC curve. The

6 predicted and measured $\theta(\psi)$ values were compared using the regression analysis

7 procedure detailed above.

8 The particle size data was used with the Williams et al. (1992) Function 4 to

9 predict values of $A$ and $B$ in equation 2. Northcote texture classes were inferred from

10 clay percentage using the clay ranges given in Northcote (1971). Then the air entry

11 potential $\left(\psi_{\mathrm{e}}\right)$ and the $b$ values were calculated from equations 3 and 4 . The predicted

$12 \theta(\psi)$ values were then compared with the measured $\theta(\psi)$ values using the regression

13 analysis procedure described previously.

\section{RESULTS AND DISCUSSION}

The van Genuchten (1980) and Campbell (1974) soil water characteristic models

18 The analysis of how well the van Genuchten and Campbell models described the

19 measured SWC data in the Bruand et al. (2003) data set is shown in Table 1. The van

20 Genuchten equation gave a better description of this range of SWC data than did the

21 Campbell equation. The sigmoidal form of equation seems more flexible than the

22 power-law form as would be expected given its greater number of variables. The

23 mean absolute error of the fitting for both equations is around $0.01 \mathrm{~m}^{3} \mathrm{~m}^{-3}$. This 
1 appears acceptable given that it is probably within normal laboratory measurement

2 error. The fitting of both equations to data from all horizons tended to have a negative

3 mean error, and when the residuals were regressed against the fitted values the slopes

4 were always negative and the intercepts positive. This indicates a systematic

5 tendency for fitted $\theta$ values to be slightly larger than the measured $\theta$ values and

6 accentuated nearer saturation. This is likely in part to reflect that measured $\theta$ values

7 close to saturation were sometimes high relative to the total porosity determined from

8 the measured clod bulk density (clod bulk density was usually measured at $-3.30 \mathrm{~m}$

9 matric potential). Measured volumetric water content values that exceeded 0.95 of

10 total porosity were removed in the data screening process but some systematic

11 measurement error probably remains.

12 The fitting results for these two equations on the Bruand et al. (2003) data set are 13 comparable to the results of Cresswell and Paydar (1996) for the Geeves et al. (1995)

14 and Forrest et al. (1985) Australian soil data. For example the overall mean absolute

15 error for fitting the Campbell equation on the two Australian data sets was

$160.010 \mathrm{~m}^{3} \mathrm{~m}^{-3}$, almost identical to that reported here for the Bruand et al. (2003) data.

17 The overall mean absolute error for fitting the van Genuchten equation on the two

18 Australian data sets was $0.007 \mathrm{~m}^{3} \mathrm{~m}^{-3}$, only slightly better than that for the Bruand et 19 al. (2003) data.

20 The simpler Campbell power-law equation is not much inferior to the van

21 Genuchten model in terms of goodness of fit on the Bruand et al. (2003) data. It also

22 has advantages due to its simplicity. It can be used in SWC prediction where soil

23 properties that are easy to measure are related to the equation parameters (e.g.

24 Williams et al. 1992). The van Genuchten function is less appropriate in this regard

25 because the larger number of equation parameters allows similar SWCs to be 
1 described by different combinations of equation parameters. Hence empirical

2 prediction of the equation parameters seems less appropriate.

3

4

(Table 1 near here)

Assessing the two-point method of Cresswell and Paydar (1996)

The two-point method application to the Bruand et al. (2003) data set resulted in a good description of the measured SWC as shown in Table 2. Using a -1.00 m matric potential wet end match point resulted in a slightly better result than a $-3.30 \mathrm{~m}$ match point but the analysis suggests either would be adequate. With the $-1.00 \mathrm{~m}$ match point, mean error is very close to zero indicating neither under nor over prediction. However, the residual analysis has negative slopes and positive intercepts indicating fitted $\theta$ values tend to be larger than the measured $\theta$ values nearer saturation. This is the same systematic error evident when the underlying Campbell model was fitted to the full measured SWC curves.

(Table 2 near here)

The two-point method is not empirically based and hence should work consistently well across different SWC data sets providing that they are well described by the Campbell SWC model. Cresswell and Paydar (1996) reported an overall mean absolute error from the two-point method of $0.014 \mathrm{~m}^{3} \mathrm{~m}^{-3}$ for the Geeves et al. (1995) and Forrest et al. (1985) data sets combined (cf. $0.016 \mathrm{~m}^{3} \mathrm{~m}^{-3}$ for the $-1.00 \mathrm{~m}$ match 
1 point in Table 2). Even though the Bruand et al. (2003), Geeves et al. (1995), and

2 Forrest et al. (1985) data sets are from very different soils, this work has shown that

3 the Campbell model and the two-point predictions are robust for each data set. The

4 small amount of variation between data sets probably reflects differences in

5 measurement methods and experimental error as much as underlying differences in

6 soil attributes.

7 The magnitude of the prediction error with the two-point method is good, given 8 that it utilises limited data. Nevertheless, the two-point fitting will result in some loss

9 of accuracy compared with functions fitted to a greater number of measured $\theta(\psi)$

10 points. The two-point method increases the reliance on the accuracy of measurement

11 of the two points that are used for interpolation or extrapolation. This work confirms

12 the value of the two-point method in improving the cost effectiveness of obtaining

13 SWC data. The 'wet-end' point (e.g. -1.0 m matric potential) can be measured using

14 simple suction tables together with 'undisturbed' soil cores. The 'dry-end' point (e.g.

$15-150 \mathrm{~m}$ matric potential) point can be measured using disturbed (ground) soil material

16 (from the same core) with pressure plate apparatus or a psychrometer. The two-point

17 method is useful in circumstances where two $\theta(\psi)$ pairs have been collected

18 previously to approximate drained upper limit (field capacity) and lower limit (wilting 19 point).

20 The two-point method is less empirical than regression-based statistical models

21 (see below) and hence more generally applicable. The analysis here confirms that

22 local calibration should not be required other than checking against $\theta(\psi)$ data

23 collected from reference sites to ensure that the SWC is well described by the

24 Campbell equation. 
1 Assessing the utility of the method of Williams et al. (1992)

2 An assessment of Function 4 of Williams et al. (1992) (Table 3, Figure 2) shows an

$3 \mathrm{R}^{2}$ value of $85.2 \%$ when measured and predicted water content values are regressed ( $n$

$4=974 \theta(\psi)$ points ) and indicates a tendency for predicted $\theta$ values to be larger than

5 the measured $\theta$ values nearer saturation but smaller than the measured $\theta$ values at the

6 dry end of the SWC. Overall the results indicate a surprisingly good prediction of the

7 Bruand et al. (2003) data given the empirical nature of the Williams approach and the

8 geographical origin of the test data. Predictions of the French SWC data using the

9 Williams equation were better than those reported by Paydar and Cresswell (1996) for

10 the Australian soil data of Geeves et al. (1995).

(Table 3 and Figure 2 near here)

14 Bruand et al. (2003) developed a class pedotransfer function using part of their 15 data set and tested it on the remaining samples. They reported a RMSE for predicting 16 water content at $-3.30 \mathrm{~m}$ and $-150 \mathrm{~m}$ matric potential of $0.044 \mathrm{~m}^{3} \mathrm{~m}^{-3}$ and $0.045 \mathrm{~m}^{3} \mathrm{~m}^{-3}$ 17 respectively. For comparison Table 3 shows an overall RMSE of $0.037 \mathrm{~m}^{3} \mathrm{~m}^{-3}$ for all 18 samples, across all measured SWC points, when predicted with Function 4 of

19 Williams et al. (1992). Note that the Bruand pedotransfer function testing was on a 20 larger number of samples (221) than was used for assessing the Williams et al. (1992)

21 function (144 samples). Our screening process excluded many samples and this

22 probably contributes to the apparent better performance of the Williams equations 23 relative to the Bruand method. 
1 These results suggest reasonable applicability of the Williams et al. (1992) method

2 to French soils and confirm that the approach of assuming a Campbell SWC model

3 and empirically predicting the slope and air entry potential has merit. Hence the

4 empirical regression equations appear transferable to different data sets from very

5 different geographical locations. The greater transferability however, might be a

6 reflection of the lower accuracy and precision of an approach using very limited data.

7 The overall mean absolute error with SWC prediction for the Bruand et al. (2003)

8 data using Williams Function 4 was $0.030 \mathrm{~m}^{3} \mathrm{~m}^{-3}$ (standard error $0.0007 \mathrm{~m}^{3} \mathrm{~m}^{-3}$ )

9 compared to the two-point method of $0.016 \mathrm{~m}^{3} \mathrm{~m}^{-3}$ (standard error $0.0005 \mathrm{~m}^{3} \mathrm{~m}^{-3}$ ), and

10 to fitting the Campbell equation to the measured data of $0.011 \mathrm{~m}^{3} \mathrm{~m}^{-3}$ (standard error

$110.0003 \mathrm{~m}^{3} \mathrm{~m}^{-3}$ ). Taking the mean absolute error as an indication of prediction

12 accuracy and the associated standard error to indicate the relative precision of

13 prediction then it is apparent that the Williams et al. (1992) method loses precision as

14 well as accuracy as compared to fitting the Campbell model to the measured data.

15 The empirical Williams method also lacks both accuracy and precision in comparison

16 to the two-point method as would be expected when relying on soil textural data for

17 input. The use of measured $\theta(\psi)$ points as input incorporate information on the wet

18 end of the SWC, the matric potential range that is influenced by soil structure and

19 therefore difficult to predict from texture alone.

20 Whether methods for predicting SWC data are of sufficient accuracy and precision

21 depends on the intended use of the data. Cresswell and Paydar (2000) used functional

22 sensitivity analysis on 66 Australian soil horizons with a soil water simulation model

23 to assess the adequacy of SWC prediction methods. Adequacy of SWC prediction

24 was assessed in terms of resulting error in prediction of drainage of water below the

25 root zone and evapotranspiration from perennial pasture in southern Victoria, 
1 Australia. Water balance error resulting from the two-point method of SWC

2 prediction was small with simulated drainage less than $5 \mathrm{~mm} \mathrm{yr}^{-1}$ different, on

3 average, from that generated using measured SWC data (drainage prediction error of

$43.6 \%$ ). The two-point method appears sufficiently accurate for many simulation

5 applications. In comparison, the use of Williams et al. (1992) Function 4 resulted in

6 an average drainage prediction error of $20 \mathrm{~mm} \mathrm{yr}^{-1}$ (or 18.0\%) (note that the errors in

7 drainage prediction reported above are calculated using estimated values of SWC,

8 which in each case are then used to estimate unsaturated hydraulic conductivity using

9 the method of Campbell (1974)). It suffices to say that indirect hydraulic property

10 prediction methods should be used carefully and with a good understanding of the

11 effect of hydraulic property prediction error on the application in question.

Strategy for soil hydraulic property characterisation

14 France and Australia have similar challenges if they are to achieve detailed soil and

15 land information at scales relevant to management decision making. Earlier work

16 (McKenzie 1991; Cresswell et al. 1999; Wösten et al. 1985, 1986) would suggest that

17 a strategy for achieving adequate coverage of soil hydraulic property data for France

18 might include an efficient sampling strategy based on the use of functional horizons

19 (Bouma 1989) and a series of reference sites where soil hydraulic properties are

20 measured comprehensively. The functional horizon method recognises the soil

21 horizon rather than the profile as the individual or building block for prediction

22 (Wösten et al. 1985; Wösten and Bouma 1992). A significant feature is the capacity to

23 create a complex range of different hydrologic soil classes from simple combinations

24 of horizon type, sequence, and thickness. The major soil horizons from a survey area

25 could be identified during a survey using functional morphological descriptors 
1 (following Wösten et al. 1985; McKenzie and Jacquier 1997). Horizons that do not

2 differ significantly in terms of their functional morphology would be combined as one

3 major horizon type for the hydraulic sampling strategy.

4 Ideally, direct, quantitative measurement of properties such as bulk density, the soil

5 water characteristic and hydraulic conductivity would be performed on several

6 examples of each of these major horizons as was done by Wösten et al. (1985) and

7 Wopereis et al. (1993). However in France, as is Australia, comprehensive

8 measurement sets such as this will only be possible on a relatively small number of

9 horizons, most appropriately those linked with a system of reference sites. At others, a

10 more economical set of soil hydraulic properties could be adopted. We refer to the

11 results from the above evaluation of SWC prediction methods on French soils and

12 suggest that such a 'basic' measurement set might include particle size distribution,

13 bulk density, and water retention at -1.0 and $-150 \mathrm{~m}$ matric potential.

14 Different soil horizons would therefore be subject to one of the following three

15 levels of hydraulic characterization (Cresswell et al. 1999):

16 1. functional morphological description (i.e. measurement of attributes with a logical 17 connection to water movement and storage such as areal porosity)

18 2. functional morphology plus a 'basic' set of hydraulic properties, to be adopted at

19 each functional horizon which is differentiated within a survey; or

203 . morphology plus comprehensive soil hydraulic characterization which would be

$21 \quad$ completed at each reference site.

22 The functional morphology, 'basic' and 'comprehensive' hydraulic property data

23 could be used with existing SWC prediction methods such as that of Bruand et al.

24 (2003) or those assessed above, or could be used to derive new pedotransfer functions. 
1 These predictive functions would subsequently be used to generate predictions of

2 hydraulic properties for all horizons and profiles in the survey for which functional 3 morphological descriptors are available. Finally, those major horizons with similar

4 hydraulic properties could be combined to reduce the total number of major horizons

5 differentiated to a number less than was initially distinguished through pedological

6 classification (e.g. Wösten et al. 1985).

\section{CONCLUSIONS}

9 The three levels of SWC characterisation considered here - fitting to measured $\theta(\psi)$

10 data, 'two-point' prediction, and empirical prediction from soil texture and bulk

11 density - all have apparent value when applied to French soils. Methods without an

12 empirical basis should be widely applicable and the analysis here supports this in

13 showing comparable results from fitting Australian and French soil data with the van

14 Genuchten and Campbell SWC equations and from prediction with the two-point

15 method. Empirical prediction methods that use texture and bulk density as inputs

16 would usually be expected to have more limited transferability. The performance of

17 the Williams et al. (1992) SWC prediction method on French soils was surprising

18 given that it was as good as on Australian soils similar to those on which it was

19 developed. Such indirect empirical methods do however lack the accuracy and

20 precision of methods that incorporate measured $\theta(\psi)$ points and will probably require

21 local calibration to achieve sufficient accuracy and precision for use in local

22 hydrological analysis.

23 Bulk density is a required input for many of the indirect empirical SWC prediction

24 methods. If core samples or clods are collected in the field for this purpose then it 
1 would seem cost effective to measure water retention at least at one matric potential

2 (e.g. $-1.0 \mathrm{~m}$ ) so that the significantly more accurate two point method can be used.

3 The second $\theta(\psi)$ point required can be easily determined on laboratory pressure plate

4 apparatus using disturbed soil material at little cost.

5 An efficient strategy for the hydraulic characterisation of soils will combine

6 comprehensive direct measurement at a small number of carefully chosen reference

7 sites, with an intermediate level of direct hydraulic characterisation that includes the

8 inputs for the two-point method (plus soil texture) at many more sites. If indirect

9 empirical pedotransfer functions are used then they can be calibrated locally against

10 the reference site data.

11 Evaluations of the performance and transferability of methods to predict soil

12 hydraulic properties contribute to the design of workable strategies for soil hydraulic

13 characterisation. Description of the functional attributes of our soils and landscapes

14 will ultimately contribute to improved management of land and water resources.

\section{ACKNOWLEDGEMENTS}

17 The authors would like to thank the Government of Australia (Department of

18 Education, Science and Training), the Embassy of France (in Australia) and the

19 Australian Academy of Science for supporting scientific collaboration between France

20 and Australia. 
2 Ahuja LR Naney JW \& Williams RD 1985. Estimating soil water characteristics from

3 simpler properties or limited data. Soil Science Society of America Journal 49,

$4 \quad 1100-1105$.

Bouma J 1989. Land qualities in space and time. In: Land qualities in space and time,

6 eds J Bouma \& AK Bregt. Proceedings of a symposium organized by the

7 International Society of Soil Science, Pudoc, Wageningen. pp. 3-13.

8 Bruand A 1990. Improved prediction of water-retention properties of clayey soils by

9 pedological classification. Journal of Soil Science 41, 491-497.

10 Bruand A Baize D \& Hardy M 1994. Prediction of water retention properties of 11 clayey soils : validity of relationships using a single soil characteristic. Soil Use 12 and Management, 10(3), 99-103.

13 Bruand A Duval O \& Cousin I 2004. Estimation des propriétés de rétention en eau des 14 sols à partir de la base de données SOLHYDRO : Une première proposition 15 combinant le type d'horizon, sa texture et sa densité apparente. Etude et Gestion 16 des Sols 11, 323-332.

Bruand A Pérez Fernández P \& Duval O 2003. Use of class pedotransfer functions

18 based on texture and bulk density of clods to generate water retention curves. Soil

19 Use and Management 19, 232-242.

20 Bruand A Duval O Gaillard H Darthout R \& Jamagne M 1996. Variabilité des

21 propriétés de rétention en eau des sols: importance de la densité apparente. Etude et 22 Gestion des Sols 3, 27-40. 
1 Campbell GS 1974. A simple method for determining unsaturated hydraulic

2 conductivity from moisture retention data. Soil Science 117, 311-314.

3 Cresswell HP \& Paydar Z 1996. Water retention in Australian soils. I. Description and

4 prediction using parametric functions. Australian Journal of Soil Research 34, 195 5212

6 Cresswell HP \& Paydar Z 2000. Functional evaluation of methods for predicting the 7 soil water characteristic. Journal of Hydrology 227, 160-172.

8 Cresswell HP McKenzie NJ \& Paydar Z 1999. A strategy for determination of 9 hydraulic properties of Australian soil using direct measurement and pedotransfer 10 functions. In: Proceedings of an International Workshop on the Characterisation 11 and Measurement of the Hydraulic Properties of Unsaturated Porous Media, eds 12 MTh van Genuchten \& FJ Leij. University of California, Riverside, CA. pp 1143131160.

14 Forrest JA Beatty J Hignett CT Pickering JH \& Williams RGP 1985. A survey of the 15 physical properties of wheatland soils in Eastern Australia. CSIRO Division of 16 Soils, Divisional Report No. 78, CSIRO, Australia. GM 1995. The physical, chemical and morphological properties of soils in the wheat-belt of southern NSW and northern Victoria. NSW Department of Conservation and Land Management/ CSIRO Division of Soils Occasional report, 21 CSIRO, Australia. models. Journal of Soil Science 38, 105-113. 
1 ISSS Working Group RB 1998. World Reference Base for Soil Resources:

2 Introduction, eds JA Deckers FO Nachtergaele \& OC Spaargaren, Edition one,

3 International Society of Soil Science (ISSS). ISRIC-FAO-ISS-Acco. Leuven,

4 Belgium.

5 McKenzie NJ 1991. A strategy for coordinating soil survey and land evaluation in

6 Australia. CSIRO Division of Soils, Divisional Report No. 114, CSIRO, Australia.

7 McKenzie NJ \& Jacquier DW 1997. Improving the field estimation of saturated

8 hydraulic conductivity in soil survey. Australian Journal of Soil Research 35, 803-

9825.

10 Minasny B McBratney AB \& Bristow KL 1999. Comparison of different approaches

11 to the development of pedotransfer functions for water retention curves. Geoderma

$1293,225-253$.

13 Monnier G Stengel P \& Fiès JC 1973. Une méthode de mesure de la densité

14 apparente de petits agglomérats terreux. Application à l'analyse des systèmes de

15 porosité du sol. Annales Agronomiques 24, 533-545.

16 Northcote KH 1971. A Factual Key for the Recognition of Australian Soils, 4th

17 Edition. Rellim Technical Publications, Glenside, South Australia.

18 Paydar Z \& Cresswell HP 1996. Water retention in Australian soils. II Prediction

19 using particle size, bulk density and other properties. Australian Journal of Soil

$20 \quad$ Research 34, 679-693.

21 Prebble RE 1970. Physical properties from 17 soil groups in Queensland. CSIRO

22 Division of Soils Technical Memorandum 10/70, CSIRO, Australia.

23 Robert M \& Tessier D 1974. Méthode de preparation des argiles des sols pour les

24 études minéralogiques. Annales Agronomiques 25, 859-882. 
1 Smettem KJR \& Gregory PJ 1996. The relation between soil water retention and

2 particle size distribution parameters for some predominantly sandy Western

3 Australian soils. Australian Journal of Soil Research 34, 695-708.

4 van Genuchten MTh 1980. A closed-form equation for predicting the hydraulic

5 conductivity of unsaturated soils. Soil Science Society of America Journal 44, 892-

6898.

7 van Genuchten MTh \& Nielsen DR 1985. On describing and predicting the hydraulic

8 properties of unsaturated soils. Annales Geophysicae 3, 615-628.

9 van Genuchten MTh Leij FJ \& Yates SR 1991. The RETC code for quantifying the

10 hydraulic functions of unsaturated soils. EPA/600/2-91/065. 93pp. R.S. Kerr

11 Environmental Research Laboratory, U.S. Environmental Protection Agency, Ada, 12 OK, USA.

13 Williams J Ross PJ \& Bristow KL 1992. Prediction of the Campbell water retention

14 function from texture, structure and organic matter. In: Proceedings of an

15 International Workshop on Indirect Methods for Estimating the Hydraulic

16 Properties of Unsaturated Soils, eds MTh van Genuchten FJ Leij \& LJ Lund,

17 University of California, Riverside, CA, USA. pp. 427-441.

18 Wopereis MCS Kropff MJ Wösten JHM \& Bouma J 1993. Sampling strategies for

19 measurement of soil hydraulic properties to predict rice yield using simulation

20 models. Geoderma 59, 1-20.

21 Wösten JHM Bouma J \& Stoffelsen GH 1985. Use of soil survey data for regional

22 soil water simulation models. Soil Science Society of America Journal 49, 1238 -

$23 \quad 1244$. 
1 Wösten JHM Bannink MH de Gruijter JJ \& Bouma J 1986. A procedure to identify

2 different groups of hydraulic conductivity and moisture retention curves for soil

3 horizons. Journal of Hydrology 86, 133-145.

4 Wösten JHM \& Bouma J 1992. Applicability of soil survey data to estimate hydraulic 5 properties of unsaturated soils. In: Proceedings of an International Workshop on

6 Indirect Methods for Estimating the Hydraulic Properties of Unsaturated Soils, eds

7 MTh van Genuchten FJ Leij \& LJ Lund, University of California, Riverside, CA, $8 \quad$ USA. pp. $463-472$. 
1 Figure captions

2

3 Figure 1. Distribution of soil texture from the samples used in this study (a sub set of

4 the data of Bruand et al. 2003).

5

6 Figure 2. Prediction of soil water characteristic data using the method of Williams et

7 al. (1992) (Function 4): (a) measured and predicted water contents for all samples $(n=$

$8974 \theta(\psi)$ points), (b) analysis of residuals.

9 
$1 \quad$ Figure 1.

2

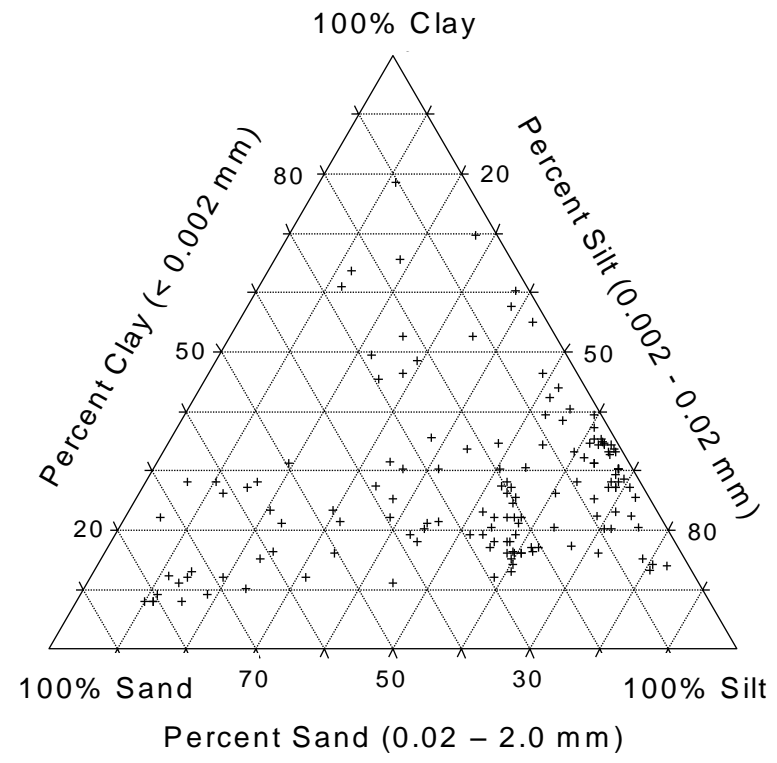

4

5 

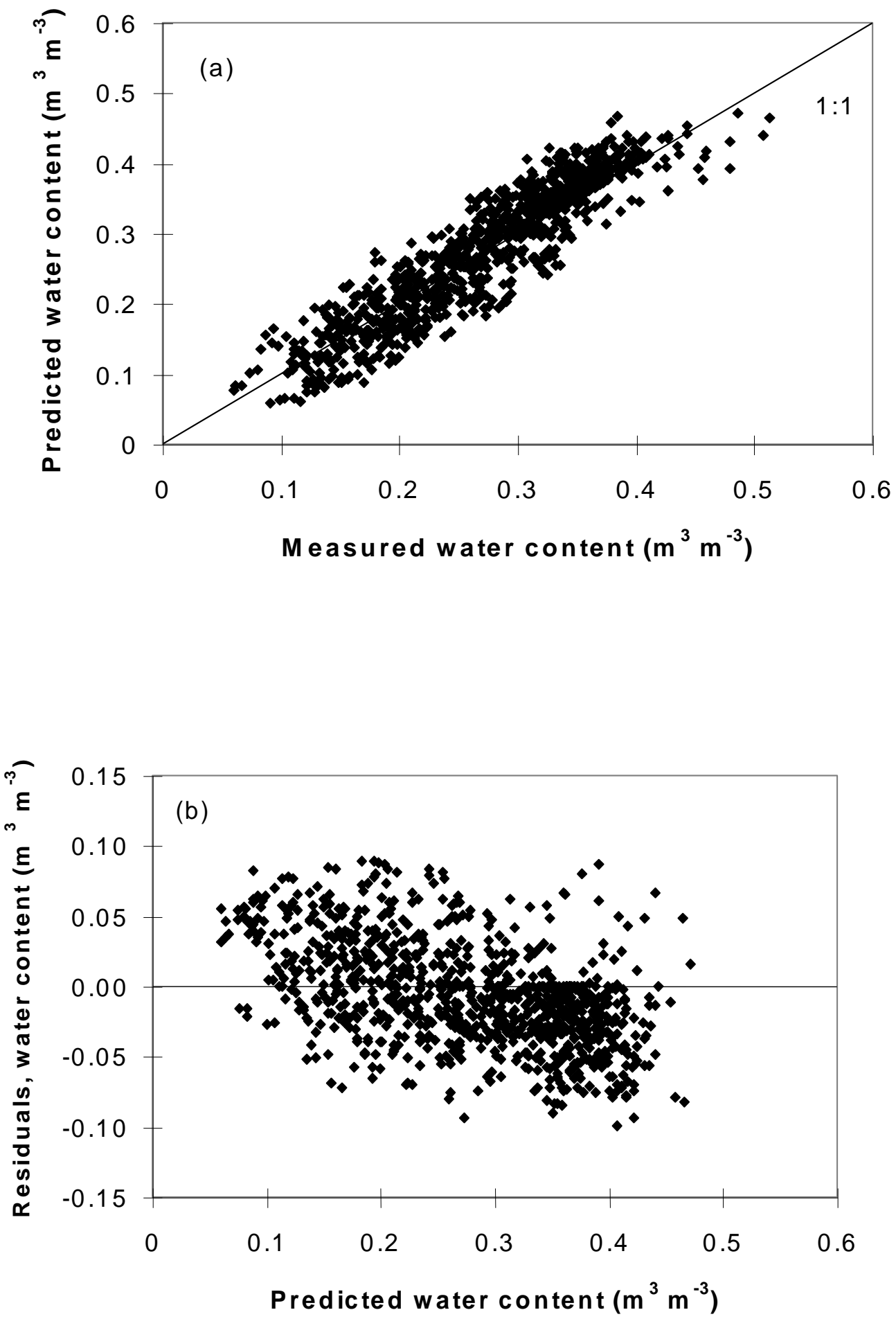

5 
1 Table 1. Assessment of the soil water characteristic models of van Genuchten (1980)

2 and Campbell (1974) using measured data from France ${ }^{\mathrm{a}}$.

van Genuchten

$\begin{array}{llllllll}\text { All samples } & 0.981 & 0.0116 & 0.009 & -0.001 & 980 & -0.013 & 0.002 \\ \text { A-horizon } & 0.978 & 0.0139 & 0.011 & -0.002 & 221 & -0.026 & 0.005 \\ \text { B-horizon } & 0.986 & 0.0083 & 0.007 & -0.001 & 444 & -0.008 & 0.002 \\ \text { C-horizon } & 0.976 & 0.0135 & 0.010 & -0.001 & 245 & -0.007 & 0.001 \\ \text { E-horizon } & 0.971 & 0.0146 & 0.012 & -0.002 & 70 & -0.024 & 0.004\end{array}$

\section{Campbell}

$\begin{array}{llllllll}\text { All samples } & 0.971 & 0.0141 & 0.011 & -0.001 & 978 & -0.016 & 0.003 \\ \text { A-horizon } & 0.966 & 0.0169 & 0.013 & -0.002 & 225 & -0.015 & 0.002 \\ \text { B-horizon } & 0.976 & 0.0109 & 0.009 & -0.002 & 437 & -0.023 & 0.005 \\ \text { C-horizon } & 0.971 & 0.0151 & 0.011 & -0.002 & 243 & -0.015 & 0.002 \\ \text { E-horizon } & 0.959 & 0.0176 & 0.015 & 0.000 & 73 & -0.006 & 0.001\end{array}$


1 Table 2. Assessment of the two-point method of Cresswell and Paydar (1996) for soil

2 water characteristic prediction using measured data from France ${ }^{\mathrm{a}}$.

Two point method: $-1.00 \mathrm{~m}$ and $-150 \mathrm{~m}$

$\begin{array}{llllllll}\text { All samples } & 0.943 & 0.0203 & 0.016 & 0.000 & 583 & -0.098 & 0.028 \\ \text { A-horizon } & 0.933 & 0.0250 & 0.020 & 0.003 & 112 & -0.093 & 0.028 \\ \text { B-horizon } & 0.946 & 0.0167 & 0.013 & 0.000 & 292 & -0.088 & 0.026 \\ \text { C-horizon } & 0.943 & 0.0211 & 0.017 & 0.000 & 141 & -0.100 & 0.027 \\ \text { E-horizon } & 0.932 & 0.0264 & 0.022 & -0.000 & 38 & -0.181 & 0.043\end{array}$

Two point method: $-3.30 \mathrm{~m}$ and $-150 \mathrm{~m}$

$\begin{array}{llllllll}\text { All samples } & 0.948 & 0.0220 & 0.017 & -0.007 & 619 & -0.111 & 0.025 \\ \text { A-horizon } & 0.946 & 0.0240 & 0.019 & -0.007 & 134 & -0.100 & 0.022 \\ \text { B-horizon } & 0.958 & 0.0175 & 0.013 & -0.008 & 283 & -0.096 & 0.022 \\ \text { C-horizon } & 0.945 & 0.0236 & 0.018 & -0.004 & 158 & -0.123 & 0.030 \\ \text { E-horizon } & 0.922 & 0.0332 & 0.026 & -0.014 & 44 & -0.202 & 0.038\end{array}$

5 number of $\theta(\psi)$ pairs. 
1 Table 3. Assessment of the method of Williams et al. (1992) for soil water

2 characteristic prediction using measured data from France ${ }^{\mathrm{a}}$.

3

Measured vs. predicted water content

Residual analysis

Williams et al. (1992) Function 4

$\begin{array}{lccccccc}\text { All samples } & 0.852 & 0.0371 & 0.030 & -0.006 & 974 & -0.194 & 0.048 \\ \text { A-horizon } & 0.873 & 0.0372 & 0.030 & 0.003 & 224 & -0.163 & 0.045 \\ \text { B-horizon } & 0.863 & 0.0332 & 0.027 & -0.011 & 438 & -0.216 & 0.054 \\ \text { C-horizon } & 0.810 & 0.0435 & 0.036 & -0.001 & 238 & -0.216 & 0.056 \\ \text { E-horizon } & 0.913 & 0.0364 & 0.029 & -0.025 & 74 & -0.105 & 0.002\end{array}$

$4{ }^{\mathrm{a}}$ RMSE is root mean squared error; MAE is mean absolute error of the residuals; $n$ is

5 number of $\theta(\psi)$ pairs. 